\title{
Relationship between serum total magnesium and serum potassium in emer- gency surgical patients in a tertiary hospital in Ghana
}

\author{
Robert Djagbletey ${ }^{1}$, Brenda Phillips ${ }^{1}$, Frank Boni ${ }^{1}$, Christian Owoo, Ebenezer Owusu-Darkwa ${ }^{1}$, \\ Papa Kobina Gyakye deGraft-Johnson ${ }^{2}$ and Alfred E. Yawson ${ }^{3}$
}

Ghana Med J 2016; 50(2): 78-83 DOI: http://dx.doi.org/10.4314/gmj.v50i2.5

\author{
${ }^{1}$ Department of Anaesthesia, University of Ghana School of Medicine and Dentistry, College of Health \\ Sciences, Accra, Ghana ${ }^{2}$ Department of Anaesthesia, Korle-Bu Teaching Hospital, Accra, Ghana \\ ${ }^{3}$ Department of Community Health, School of Public Health, College of Health Sciences, University of Ghana, \\ Accra, Ghana \\ Corresponding author: Dr Robert Djagbletey \\ E-mail: r_djag@yahoo.com
}

Conflict of interest: None declared

\section{SUMMARY}

Introduction: Potassium and magnesium are the two most abundant intra-cellular cations. They play pivotal roles in many essential biological processes. Deficiencies of these electrolytes are of clinical importance in hospitalised patients.

Aim: To determine the relationship between serum total magnesium and potassium levels in adult patients requiring an emergency intra-abdominal surgery and the clinical utility of this relationship in the care of patients.

Methods: A cross sectional study was conducted over a five month period at the Korle-Bu Teaching Hospital. All 101 adult patients admitted for emergency intra-abdominal surgery, who met the inclusion criteria and gave informed consent, were consecutively recruited and enrolled into the study. Patients' characteristics preoperative total serum magnesium, serum potassium and albumin levels were determined. Regression analysis and correlation coefficients were used to determine the relation between serum magnesium and potassium. Analysis was done using SPSS version 20.

Results: Mean serum total magnesium and serum potassium were $0.66 \pm 0.20 \mathrm{mmol} / \mathrm{L}$ and $3.79 \pm 0.65 \mathrm{mmol} / \mathrm{L}$ respectively. There was a significant but weak positive correlation between serum hypokalaemia and serum magnesium levels. Pearson's correlation coefficient ( 2 tailed) was $0.21, \mathrm{R}^{2}=0.04, \mathrm{p}=$ value 0.038 . Analysis generated a regression model: $[\mathrm{Mg}]=0.06[\mathrm{~K}]+0.42 \mathrm{mmol} / \mathrm{L}$, with a $\mathrm{p}$-value $=0.038$.

Conclusion: A mathematical relationship was found between serum total magnesium and serum potassium among adult patients who require emergency intra-abdominal surgery. However, it had limited clinical utility.

Funding: None declared

Keywords: Potassium, magnesium, electrolyte, preoperative period

\section{INTRODUCTION}

Potassium and magnesium are the two most abundant intra-cellular cations in the body. ${ }^{1}$ They play vital roles in the functioning of excitable tissues such as nerves, skeletal muscle and cardiac muscle. ${ }^{2}$ They also play pivotal roles in many other essential biological processes such as cellular energy metabolism, cell replication and protein synthesis. ${ }^{3,4}$ Whereas intracellular potassium serves as a catalyst in a few enzymatic reactions, magnesium serves as a co-factor in more than 300 enzymatic reactions, most importantly those involved in the formation and usage of adenosine triphosphate and nucleic acid synthesis. ${ }^{1,2}$
Deficiencies of these electrolytes are, however, not uncommon in hospitalised patients. Hypokalaemia has been found in $6.7-20 \%$ of hospitalized patients ${ }^{5,6}$ majority being surgical patients. While magnesium deficiency has been found in $7-11 \%$ of hospitalized patients ${ }^{7}$ but it may be as high as $65 \%$ in Intensive Care patients. ${ }^{8}$ Hypomagnesaemia and hypokalaemia have both been associated with poor prognosis and increased mortality in the acutely ill. ${ }^{9,10,11}$ Hypokalaemia has been found to be frequently associated with hypomagnesaemia. Forty-two to sixty-one percent of hypokalaemic patients are also hypomagnesaemic. ${ }^{7,12}$ 
Some studies have, however, found no correlation between serum magnesium levels and serum potassium levels. ${ }^{13,14}$ Whang et al described the phenomenon of "refractory potassium repletion" which is the inability to correct hypokalaemia in the presence of unrecognized and continuing magnesium deficiency. ${ }^{12}$

Hypomagnesaemia like hypokalaemia may result in muscular weakness and lethal cardiac dysrhythmias. Furthermore hypomagnesaeamia could lead to altered sensorium, tetany and seizures. ${ }^{1}$

Despite the impact of hypomagnesaemia on morbidity and mortality of patients and of the effectiveness of potassium replacement therapy, serum magnesium, unlike serum potassium, is not routinely determined preoperatively at the Korle-Bu Teaching Hospital and most other health facilities in Ghana. Additional cost implications both for the institution and the patient may be a significant contributory factor.

The aim of this study was to determine the relationship between serum potassium and magnesium levels in adult general surgical patients requiring an emergency intra-abdominal surgery and whether serum potassium levels can be used to predict serum total magnesium levels in the clinical care of patients.

\section{METHODS}

A cross sectional study was conducted at the main surgical theatre suite of the Korle-Bu Teaching Hospital (KBTH), the largest tertiary health care facility in Ghana, between November 2012 and April 2013. The KBTH has a bed capacity of 2000 and over 4000 staff. On average 29,757 clients were seen monthly at the outpatients with an average daily outpatient attendance of 1500 and daily in-patient admissions of 150 . On average 23 adult patients per month are admitted who require emergency intra-abdominal surgery at KBTH.

After approval by the institutional Ethical and Protocol review Committee and clearance by Management, all general surgical patients between the ages of 18-70 years, requiring emergency abdominal surgery, admitted at KBTH who gave informed consent, were selected consecutively and enrolled in the study. Pregnant women and patients with chronic kidney disease were excluded. All eligible patients attended to in the hospital between November 2012 and April 2013 were recruited consecutively i.e. all eligible patients were included in the study.

In hospitalised patients, the prevalence of hypokalaemia has been found to be up to $20 \%{ }^{6}$ while that of hypomagnesaemia is between $7-11 \%{ }^{7}$
For this cross sectional study, using the incidence of hypomagnesaemia at the $95 \%$ confidence level and power of $90 \%$, a total of 101 patients were enrolled.

A structured questionnaire was used to collect sociodemographic and medical data of the patients', including the definitive surgery done. A six (6) millilitre blood sample was taken, into gel separator tubes without the use of a tourniquet, just before induction of anaesthesia, for the determination of the preoperative serum concentrations of magnesium and potassium.

Agitation or shaking of the whole blood was avoided to prevent haemolysis of the sample. Samples were centrifuged at 5000 revolutions per minute (rpm) to obtain the serum. All laboratory investigations were done at a single site (i.e. the National Cardio-Thoracic Centre laboratory, of KBTH).

Serum total magnesium was determined by photometry using xylidyl blue. Serum potassium concentration was determined by direct ion selective method using an auto analyzer (Starlyte ${ }^{\mathrm{TM}} \mathrm{V}$ ISE, Alfa Wassermann, from Diagnostic Technologies LLC, Netherlands). Serum magnesium and albumin were determined using Eos Bravo forte auto analyzer, from Hospitex Diagnostics, Italy.

Serum potassium, magnesium and albumin levels were categorised as hypokalaemia, hypomagnesaemia and hypoalbuminaemia, respectively, if the serum levels were below the reference range (table 2). Results were categorised as normo-kalaemia, normo-magnesaemia and normo-albuminaemia, when the values were within the reference ranges. Values above the reference range were categorised as hyperkalaemia, hypermagnesaemia and hyperalbuminaemia for serum potassium, total serum magnesium and albumin respectively.

About a third of serum magnesium is bound to proteins especially albumin. Changes in serum albumin level, therefore, may affect serum total magnesium concentration and this informed our decision to determine serum albumin levels as well Serum potassium was determined for 101 patients while serum total magnesium and albumin were determined for 100 patients (due to inadequate samples in two different patients).

\section{Data Handling}

Data was treated with a high level of confidentiality. Unique identifiers and codes were employed to depersonify the participants and used for computer-based data entry. In all cases, questionnaire and documentations were kept securely locked. 
Computerized records of the study were stored in password-protected files accessible to the lead investigator only.

\section{Data Analysis:}

Patient's characteristics and preoperative total serum magnesium, serum potassium and albumin levels in patients were determined using simple descriptive statistics (frequency, proportion and ratio) and means \pm standard deviations. Chi square was used for comparison of categorical variables and Pearson's correlation was used to assess relationship between continuous variables. Logistic regression was used to describe the relationship between serum potassium and magnesium at the $95 \%$ confidence level ( $p$-value of $<$ 0.05). Data was captured using Microsoft Access 2007 Database. Analysis was done with Statistical Package for the Social Sciences (SPSS) software version 20.0.

\section{Ethical considerations:}

The Ethical and Protocol Review Committee of the University of Ghana Medical School approved the study. The study also received clearance from the Management of the Korle-Bu Teaching Hospital and Heads of Clinical units where the study was conducted.

\section{RESULTS}

A total of 101 patients were enrolled in the study with a mean age of $42.75 \pm 15.67$ years and female: male ratio of $1: 1.55$.

Table 1 Distribution of emergency intra-abdominal surgery done for patients.

\begin{tabular}{|c|c|c|}
\hline & Frequency & Percentage $(\%)$ \\
\hline \multicolumn{3}{|l|}{ Definite surgeries } \\
\hline $\begin{array}{l}\text { Obstructed/ strangulated hernia } \\
\text { repair }\end{array}$ & 25 & 24.7 \\
\hline Appendicectomy & 20 & 19.8 \\
\hline $\begin{array}{l}\text { Resection and anastomosis of } \\
\text { bowel }\end{array}$ & 14 & 13.9 \\
\hline Adhesiolysis & 13 & 12.9 \\
\hline Closure of GIT perforation & 9 & 8.9 \\
\hline $\begin{array}{l}\text { Drainage of intra-abdominal } \\
\text { abscess } \pm \text { appendicectomy }\end{array}$ & 8 & 7.9 \\
\hline $\begin{array}{l}\text { Resection and anastomosis }+ \\
\text { hernia repair }\end{array}$ & 2 & 2.0 \\
\hline Others & 10 & 9.9 \\
\hline Total & 101 & 100.0 \\
\hline
\end{tabular}

The blood samples from two patients were found to be inadequate and were thus excluded from laboratory analysis. Hernia repair was the most frequent surgery done, nearly a quarter of all the surgeries. Appendicectomy was $19.6 \%$ of surgeries done, resection and anastomosis of bowel (13.7\%) and adhesiolysis (12.7\%).

The standard chemistry reference range of the National Cardio-Thoracic Centre laboratory, mean and standard deviation of serum potassium, magnesium and albumin of patients in the Korle-Bu Teaching Hospital is as shown in Table 2.

Table 2 Descriptive and reference range for serum potassium, magnesium and albumin.

\begin{tabular}{lll}
\hline & Mean \pm s.d & Reference range \\
\hline Potassium(mmol/L) & $3.79 \pm 0.65$ & $3.5-5.0$ \\
Magnesium(mmol/L) & $0.66 \pm 0.20$ & $0.74-1.03$ \\
Albumin(g/dl) & $35.13 \pm 8.09$ & $36.0-52.0$ \\
\hline
\end{tabular}

Thirty-five patients representing $61.4 \%$ were normokalaemic, $34.6 \%$ were hypokalaemic whilst $4 \%$ were hyperkalaemic. Thirty per cent of patients had normal magnesium levels. The prevalence of hypomagnesaemia among the patients was $68.0 \%$, while $2.0 \%$ were hypermagnesaemic. Forty-seven percent of patients were hypoalbuminaemic and fifty-three percent had normal serum albumin levels.

As shown in Table 3 , only $16.2 \%$ of patients did not have serum albumin or magnesium abnormalities. Thirty-five percent of the patients were hypomagnesaemic but had normal serum albumin. $14.1 \%$ of patients had low serum albumin but normal magnesium levels. There was no association between magnesium status and albumin status as depicted by a Chi square of 0.02 and a p-value of 0.992 .

Only $24.0 \%$ of patients did not have any abnormality in the serum potassium or magnesium levels. Thirty-one patients were both hypokalaemic and hypomagnesaemic. Of the 35 patients that were hypokalaemic, 31 $(88.6 \%)$ were hypomagnesaemic. Of the 68 patients that had hypomagnesaemia, 31 (45.5\%) were hypokalaemic. There was significant association between the potassium status and magnesium status as depicted by Chi-square of 10.99 , p-value $=0.027$.

Serum potassium - magnesium relationship: There was a significant positive correlation between serum potassium and serum magnesium levels. Pearson's correlation coefficient ( 2 tailed) of $0.21, \mathrm{R}^{2}=0.04, \mathrm{p}=$ value 0.038 as shown in Figure 1.

On regression analysis, a model: $y=\beta_{0}+\beta_{1}^{x}$ was obtained with an F-value of 4.43 and a p-value of 0.038 . Where, $\mathrm{y}=$ serum magnesium concentration $[\mathrm{Mg}], \beta_{0}$ $=0.42, \beta_{1=0.06}$

$\boldsymbol{x}=$ serum potassium concentration $[\mathrm{K}]$

The model thus yielded:

$[\mathrm{Mg}]=0.06[\mathrm{~K}]+0.42 \mathrm{mmol} / \mathrm{L}$ 
Table 3 Comparison of Magnesium, potassium and albumin status among patients

\begin{tabular}{|c|c|c|c|c|c|c|c|}
\hline \multirow{4}{*}{ Albumin status } & \multirow{4}{*}{$\begin{array}{l}\text { Normo } \\
\text { Hypo }\end{array}$} & \multicolumn{3}{|c|}{ Magnesium status } & \multirow[t]{2}{*}{ Total } & \multirow{2}{*}{$\begin{array}{l}\chi^{2} \text { value } \\
\text { and (df) }\end{array}$} & \multirow[t]{2}{*}{ p-valu } \\
\hline & & Normo & Нypo & Hyper & & & \\
\hline & & $16(16.2)$ & $35(35.4)$ & $1(1.0)$ & $52(52.5)$ & \multirow{2}{*}{$0.02(2)$} & \multirow{2}{*}{0.992} \\
\hline & & $14(14.1)$ & $32(32.3)$ & $1(1.0)$ & $47(47.5)$ & & \\
\hline \multicolumn{8}{|c|}{ Magnesium status by potassium status } \\
\hline & & \multicolumn{3}{|c|}{ Magnesium status } & Total & \multirow{6}{*}{$\begin{array}{l}\chi^{2} \text { value } \\
\text { and (df) } \\
10.99(4)\end{array}$} & \multirow[t]{2}{*}{ p-value } \\
\hline \multirow{4}{*}{ Potassium status } & & Normo & Нуро & Hyper & & & \\
\hline & Normo & $24(24.0)$ & $35(35.0)$ & $2(2.0)$ & $61(61.0)$ & & \multirow[t]{4}{*}{0.027} \\
\hline & Нуро & $4(4.0)$ & $31(31.0)$ & $0(0.0)$ & $35(35.0)$ & & \\
\hline & Hyper & $2(2.0)$ & $2(2.0)$ & $0(0.0)$ & $4(4.0)$ & & \\
\hline Total & & $30(30.0)$ & $68(68.0)$ & $2(2.0)$ & $100(100.0)$ & & \\
\hline
\end{tabular}

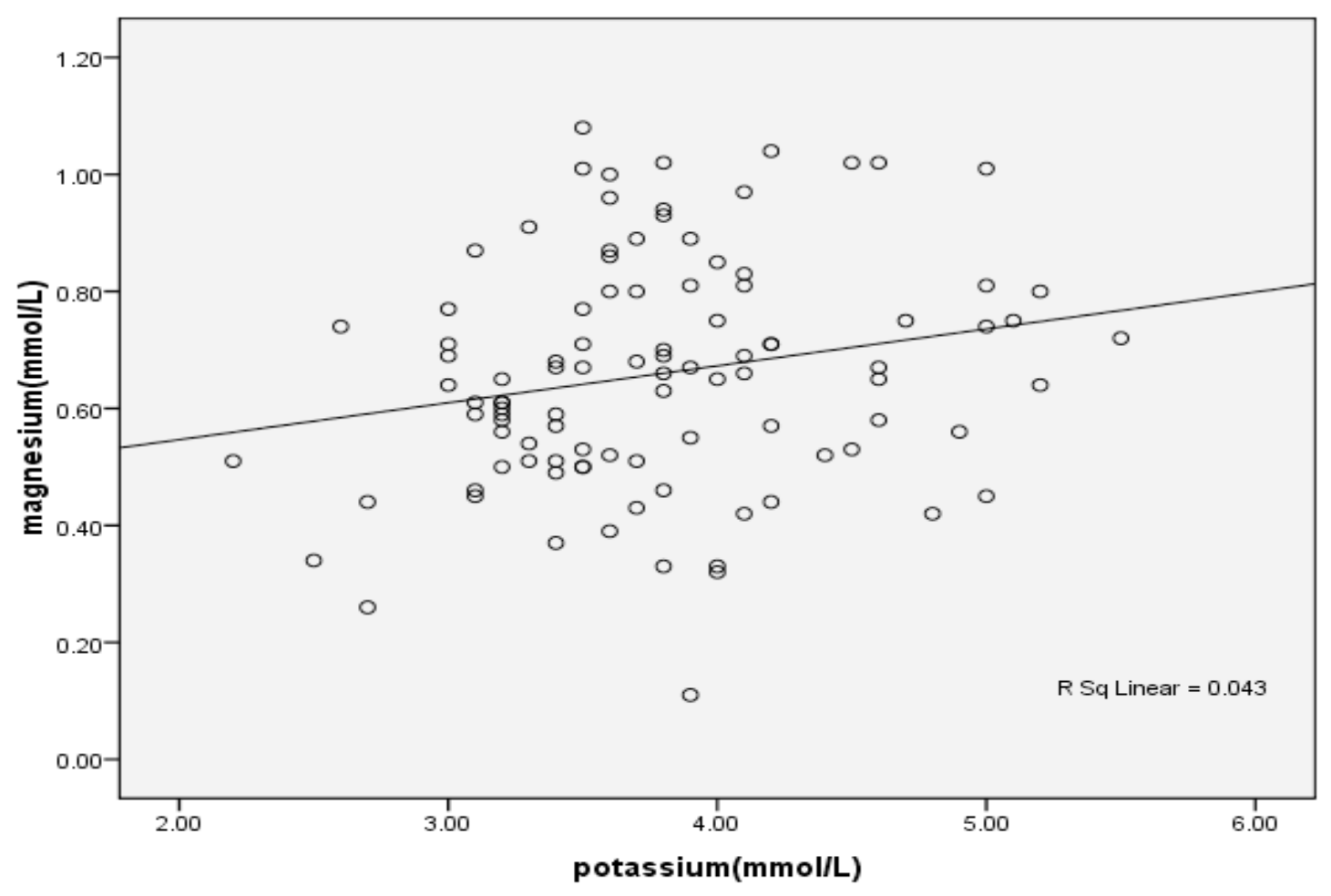

Figure 1 Correlation between serum potassium and serum total magnesium levels

\section{DISCUSSION}

The results indicated that there was a mathematical relationship between serum total magnesium and serum potassium. However, the clinical utility of this model was limited. The prevalence of hypokalaemia from the study was found to be $34.6 \%$. Of the patients found to be hypokalaemic, as many as $88.6 \%$ had associated hypomagnesaemia. This was much higher than the $42-$ $61 \%$ reported in the literature. ${ }^{12}$ In addition, the analysis showed a significant association between the potassium status and magnesium status. A significant but weak positive correlation was found between serum total magnesium and serum potassium levels [Pearson's correlation coefficient $(2$ tailed $)=0.021]$ similar to the findings of Boyd and co-workers. ${ }^{15}$
Investigating this relationship further, a regression model was obtained:

$[\mathrm{Mg}]=0.06[\mathrm{~K}]+0.42 \mathrm{mmol} / \mathrm{L}$, with a $\mathrm{p}-$ value $=0.038$

The regression model may not be clinically useful because inputting the reference range for potassium (3.5$5.0 \mathrm{mmol} / \mathrm{L}$ ) yields an expected reference range of 0.63 $-0.72 \mathrm{mmol} / \mathrm{L}$ for magnesium.

This implies that all normo-kalaemic patients would be predicted as being hypomagnesaemic and only when a patient has a hyperkalaemia of above $5.3 \mathrm{mmol} / \mathrm{L}$ would the model predict normal magnesium level. 
Thus despite the statistical significance, the regression model would not be clinically useful. This may be due to the wide scatter of the points around the line of best fit in the correlation graph (figure 1 ) and the $\mathrm{R}^{2}$ value of 0.04 obtained. This implies serum potassium levels may account for only $4 \%$ in the variability of serum total magnesium levels. Hence it would be difficult to predict serum total magnesium levels using only serum potassium levels.

Serum potassium level was however, found to have a significant predictive value for hypomagnesaemia in adult surgical patients requiring emergency intraabdominal surgery ( $p$-value $=0.001$ ), with an Odd's ratio of 9.21 and a confidence interval of 2.42 -35.09.

Magnesium plays an important role in electrolyte homeostasis and hypomagnesaemia is known to be associated with other electrolyte imbalance especially hypokalaemia. Magnesium is necessary for the activation of ion-ion /ATPase pumps which mediate the transfer of ions across cell membranes. Reduced magnesium levels leads to the impairment or reduced function of these pumps. Intra-cellular hypomagnesaemia has been postulated to lead to reduced functioning of the $\mathrm{Na}^{+}$$\mathrm{K}^{+}$/ATPase pump with resultant efflux of potassium into extra-cellular fluid which is excreted in the urine. ${ }^{16}$

There is also evidence that the ATP-dependent renal outer medullary potassium (ROMK) channel in the distal tubules increases potassium secretion in the presence of hypomagneaemia. ${ }^{17}$ The high prevalence of hypomagnesaemia may thus have contributed to the development of hypokalaemia in adult general surgical patients who require emergency laparotomy. These factors may have contributed to the relationship observed between serum potassium and magnesium. Less than half of all hypomagnesaemic patients were also hypokalaemic.

Thus determining magnesium levels only among hypokalaemic patients would risk missing majority of the hypomagnesaemic patients. It would thus be prudent to routinely test for magnesium in all adult patients who require emergency laparotomy and not just in those who are hypokalaemic.

Failure to detect and correct concomitant hypomagnesaemia may lead to refractory potassium repletion. ${ }^{12}$ Thus patients with both hypokalaemia and hypomagnesaemia, correcting the potassium alone would be difficult without correcting the associated magnesium deficiency. Often symptoms of hypomagnesaemia are nonspecific ${ }^{13}$ and may be attributed to the other electrolyte imbalances, especially hypokalaemia, which is a frequent association. ${ }^{7}$ Hypomagnesaemia should therefore be suspected and corrected in hypokalaemic patients.

Magnesium is known to bind to proteins especially albumin, therefore changes in serum albumin level may affect serum total magnesium concentration. Similar to findings of Koch, ${ }^{18}$ Huijgen, ${ }^{19}$ Chernow ${ }^{13}$ and their coworkers, this study found no correlation between serum total magnesium and serum albumin. It is thus not possible to calculate serum total magnesium using serum albumin levels.

The analysis of the relationship between serum albumin and magnesium indicated that serum albumin levels ranged from $14.7 \mathrm{mg} / \mathrm{dl}$ to $54.4 \mathrm{mg} / \mathrm{dl}$. The three lowest albumin values were obtained in: two patients with obstructed / strangulated hernia with a strong history of alcohol abuse (consuming more than 40 units of alcohol per week) and a patient with intestinal obstruction secondary to an advanced colonic tumour with liver metastasis. Liver dysfunction secondary to metastatic liver disease and alcoholic liver damage may probably account for the low serum albumin levels in these patients.

Cases frequently associated with electrolyte abnormalities such as gastro-intestinal perforations, intraabdominal abscesses and those requiring resection and anastomosis were in the minority in this study. This could have adversely impacted on the results of the study. The analysis measured and used total serum magnesium and not the metabolically active ionised magnesium which may perhaps be more related to ionised potassium. The methods for assessing ionised magnesium were not readily available. This constituted a limitation and further studies may be required.

\section{CONCLUSIONS}

There was a significant but weak positive correlation between serum potassium and magnesium levels in patients who required emergency intra-abdominal surgery. The mathematical relationship found between serum total magnesium and serum potassium, however, had limited clinical utility. Serum total magnesium levels cannot therefore be predicted solely by serum potassium levels.

Routine determination of total serum magnesium levels and correction of abnormalities may be necessary to prevent morbidity and mortality associated with hypomagnesaemia in patients who require emergency intraabdominal surgery.

Since the methods for assessing ionised magnesium were not readily available and could have adversely impacted the results, further studies may be required. 


\section{ACKNOWLEDGEMENT}

We are thankful to all health workers and patients in the clinical departments of the Korle-Bu Teaching Hospital who participated in the study and for the support received by staff of the Department of Anaesthesia, University of Ghana School of Medicine and Dentistry, College of Health, Sciences, University of Ghana, and staff of the National Cardiothoracic Centre Laboratory, Korle-Bu Teaching Hospital, Accra, Ghana. We also wish to acknowledge the help of our research assistants Mr George Aryee and Mr Raymond Essuman.

\section{REFERENCES}

1. Swaminathan R. Magnesium Metabolism and its Disorders. Clin Biochem Rev. 2003;24(2):47-66.

2. Parthasarathy S, Ravishankar M. Potassium Ion and Anaesthetic Implications chronic renal failure the stool potassium increases by. J Anesth Clin Pharmacol. 2007;23(2):129-44.

3. Kraft MD, Btaiche IF, Sacks GS, Kudsk K a. Treatment of electrolyte disorders in adult patients in the intensive care unit. Am J Heal Pharm. 2005;62(16):1663-82.

4. Jahnen-Dechent W, Ketteler M. Magnesium basics. Clin Kidney $J$ [Internet]. 2012 Mar 2 [cited 2015 Jan 30];5(Suppl 1):i3-14. Available from: http://ckj.oxfordjournals.org/cgi/doi/10.1093/ndtplu s/sfr163

5. Eliacik E, Yildirim T, Sahin U, Kizilarslanoglu C, Tapan U, Aybal-Kutlugun A, et al. Potassium Abnormalities in Current Clinical Practice: Frequency, Causes, Severity and Management. Med Princ Pract [Internet]. 2015;24(3):271-5. Available from: http://www.karger.com/?doi=10.1159/000376580

6. Gennari FG. Current concepts: Hypokalaemia. $N$ Engl J Med. 1998;339(7):451-8.

7. Whang R, Oei TO, Aikawa JK, Watanabe a, Vannatta J, Fryer a, et al. Predictors of clinical hypomagnesemia. Hypokalemia, hypophosphatemia, hyponatremia, and hypocalcemia. Arch Intern Med. 1984;144(9):1794-6.

8. Ryzen E, Wagers PW, Singer FR RR. Magnesium homeostasis in critically ill patients. Magnesium. 1989;8(3-4):201-12.

9. Rubeiz GJ, Thill-Baharozian, Mary RN, Hardie DRN CR. Association of hypomagnesemia and mortality in acutely ill medical patients. Crit Care Med. 1993;21:203-9.

10. Safavi M, Honarmand A. Admission hypomagnesemia--impact on mortality or morbidity in critically ill patients. Middle East $J$ Anesthesiol. 2007;19(3):645-60.

11. Hessels L, Hoekstra M, Mijzen LJ, Vogelzang M, Dieperink W, Lansink AO, et al. The relationship between serum potassium, potassium variability and in-hospital mortality in critically ill patients and a before-after analysis on the impact of computerassisted potassium control. Crit Care [Internet]. 2015;19(1):1-11. Available from: http://ccforum.com/content/19/1/4

12. Whang R, Whang DD RM. Refractory potassium repletion: a consequence of magnesium deficiency. Arch Intern Med. 1992;152(1):40-5.

13. Chernow B, Bamberger S, Stoiko M, Vadnais M, Mills S, Hoellerich V WA. Hypomagnesemia in patients in postoperative intensive care. Chest [Internet]. 1989 Feb 1 [cited 2015 Mar 16];95(2):391. Available from: http://journal.publications.chestnet.org/article.aspx? doi $=10.1378 /$ chest.95.2.391

14. Deheinzelin D, Negri EM, Tucci MR, Salem MZ, da Cruz VM, Oliveira RM, Nishimoto IN HC. Hypomagnesemia in critically ill cancer patients : a prospective study of predictive factors. Braz J Med Biol Res. 2000;33:1443-8.

15. Boyd JC, Bruns DE, Wills MR. Frequency of Hypomagnesemia in Hypokalemic States. Clin Chem. 1983;29(1):178-9.

16. Solomon R. Disorders of potassium and magnesium homeostasis. Semin Nephol. 1987;7(3):253-62.

17. Huang C-L, Kuo E. Mechanism of hypokalemia in magnesium deficiency. $J$ Am Soc Nephrol. 2007;18(10):2649-52.

18. Koch SM. The simultaneous measurement of ionized and total calcium and ionized and total magnesium in intensive care unit patients. J Crit Care. 2002;17(3):203-5.

19. Huijgen HJ, Soesan M, Sanders R, Mairuhu WM, Kesecioglu J, Sanders GT. Magnesium Levels in Critically Ill Patients What Should We Measure? Am J Clin Pathol. 2000;114(5):688-95. 